\title{
MALARIA VECTOR PRODUCTIVITY IN RELATION TO THE HIGHLAND ENVIRONMENT IN KENYA
}

\author{
NOBORU MINAKAWA, ELIZABETH OMUKUNDA, GUOFA ZHOU, ANDREW GITHEKO, AND GUIYUN YAN* \\ Center for Tropical Infectious Diseases, Institute of Tropical Medicine, Nagasaki University, Nagasaki, Japan; Climate and Human \\ Health Research Unit, Center for Vector Biology and Control Research, Kenya Medical Research Institute, Kisumu, Kenya; \\ Department of Biological Sciences, State University of New York, Buffalo, New York
}

\begin{abstract}
The reasons for the resurgence of malaria in the African highlands have been subject of debate. Because vector abundance is important for malaria transmission, gaining a better understanding of vector biology is a key to understanding the mechanisms of highland malaria. We studied vector productivity in relation to the highland environment and compared productivity between lowland and highland sites. We found lower vector productivity in the highland and in wetlands where the temperature was lower. Immature stage development time was significantly longer in the highland site. Development time was significantly shorter in aquatic habitats in cultivated areas than in wetlands, and survival rate was significantly higher in cultivated areas. Fecundity was significantly lower in the highland site. These findings suggest that changes in local temperature and land use contribute to an increase of malaria vectors in the highland.
\end{abstract}

\section{INTRODUCTION}

Malaria, a major human health threat, occurs globally in tropical and sub-tropical regions. The threat is mounting, a fact witnessed by increased numbers of malaria outbreaks in the Kenyan highlands (elevation $>1,500 \mathrm{~m}$ ), where malaria was previously rare. ${ }^{1,2}$ Malaria outbreaks occurred sporadically in the highlands of western Kenya from the 1920s to the 1950s. ${ }^{3,4}$ Since 1988, however, malaria epidemics have occurred with heightened frequency throughout the Kenyan highlands, causing serious mortality and morbidity. ${ }^{1,2}$

Vector densities and transmission intensity in the highlands are generally much lower than in the adjacent lowland areas. ${ }^{4-6}$ During the 1998 malaria epidemics in the highland of southwestern Uganda, the density of Anopheles gambiae s.l. was reported as low as 0.25 mosquitoes per house. ${ }^{5,7}$ On the other hand, the perennial malaria transmission in the lowlands has been attributed to high vector densities throughout the year. ${ }^{8}$ Inhabitants of the basin region of Lake Victoria in western Kenya experience up to 300 infective bites per year. ${ }^{9,10}$ Recent studies suggested that residents of highland areas generally lack immunity to Plasmodium falciparum and are particularly vulnerable to malaria infection. ${ }^{11,12}$ The proportion of asymptomatic individuals is usually lower in highlands than in high-transmission areas where there is small among-season variation in P. falciparum prevalence and parasite densities. ${ }^{13}$ Thus, a small increase in the abundance of vectors may lead to a significant malaria outbreak in the highlands.

An increase in malaria vectors in the highlands can be partially attributed to changes in land cover. ${ }^{14-17}$ Larvae of malaria vectors occur more frequently in temporary sun-lit pools in cultivated areas than in indigenous forests and natural wetlands characterized by tall aquatic plants such as papyrus (Cyperus papyrus). ${ }^{18,19}$ Recent studies also have identified correlations between malaria incidence and climatic factors. Malaria epidemics in the highlands are associated with elevated minimum temperature in Ethiopia. ${ }^{20}$ In some highland sites of East Africa, climate variability (temperature and rain-

* Address correspondence to Guiyun Yan, Department of Biological Sciences, State University of New York at Buffalo, NY 14260. E-mail: gyan@buffalo.edu fall) could explain a significant proportion of incidence of hospital malaria cases. ${ }^{21}$ Thus, recent land modifications and climate changes may alter conditions in a manner that favors vector survival and production.

These findings suggest that malaria transmission is more susceptible to environmental changes in the highlands than in the lowlands because vector production is apparently limited by the cool highland climate. ${ }^{6}$ Production of malaria vectors is determined by their development time, survival rate, and fecundity, as well as habitat availability. It is well known that temperature is the major factor affecting these biologic features under laboratory conditions. ${ }^{22,23}$ However, little is known about the development time, survival rate, and fecundity of malaria vectors in the highlands. The aim of this study was to examine these biologic features in malaria vectors at highland and lowland sites. Gaining a better understanding of vector biology is a key to understanding the mechanisms of highland malaria. The biologic information is also useful for developing effective vector control methods in the highlands. Because malaria vaccine development is slow, and parasite resistance to anti-malarial drugs is developing rapidly, vector control is still the most practical method for reducing malaria transmission in developing countries. ${ }^{24,25}$

\section{MATERIALS AND METHODS}

Study sites. We studied development time, survival, and fecundity of $A$. gambiae sensu stricto, the primary malaria vector in Africa, to estimate vector productivity in a highland site (Marani in Kisii district: 1,500-1,650 $\mathrm{m}$ above sea level) and in a lowland site (Kombewa in Kisumu district: 1,200 m above sea level) in western Kenya. Marani $\left(34^{\circ} 48^{\prime} \mathrm{E}, 00^{\circ} 35^{\prime} \mathrm{S}\right)$ is located on the highland plateau adjacent to the Lake Victoria Basin and $17 \mathrm{~km}$ north of Kisii. Malaria epidemics have occurred frequently in this area for the last 15 years. Kombewa $\left(34^{\circ} 30^{\prime} \mathrm{E}, 00^{\circ} 07^{\prime} \mathrm{S}\right)$ is located in the malaria holoendemic area of the Lake Victoria Basin and $62 \mathrm{~km}$ northwest of Marani. A study area $(4 \times 4 \mathrm{~km})$ was established within each site. Although both areas have experienced extensive deforestation and wetland reclamation because of recent rapid population growth, a few patches of wetlands still remained along streams. Larvae of $A$. gambiae occur mainly in ditches and 
puddles in farmlands and pastures that were converted from forests and wetlands. ${ }^{18,19}$

Immature stage development and survival. In addition to comparing vector productivity between the highland and lowland sites, we determined whether land cover types (cultivated areas and wetlands) affect production of A. gambiae. ${ }^{18,19}$ We also determined whether initial densities of larvae affect productivity.

A total of 36 semi-natural habitats (6 replicates per land cover type and density combination) were created using plastic washbasins (35 $\mathrm{cm}$ in diameter and $15 \mathrm{~cm}$ deep) at each study site. Two kilograms of dry soil was added to each washbasin. The dry soil was collected from a farmland in Kombewa and used for both sites. Two holes $(3 \mathrm{~cm}$ in diameter) were created near the top edge of each washbasin to maintain a constant water level when it rained. The holes were covered with a screen (mesh size $=200 \mu \mathrm{m}$ ) to prevent larvae from being washed away. One day before the experiment, the washbasins were flooded with rainwater. Rainwater was collected 1-4 days before the experiment and stored in a black plastic container in the laboratory. Larvae were obtained at $\sim 4$ hours old from the mosquito colony maintained in the insectary at the Kenya Medical Research Institute in Kisian, Kisumu district, western Kenya. Six washbasins received 20 larvae. Three washbasins with 20 larvae each were placed in randomly selected aquatic habitats in each of the two land cover types within each study area. Similarly, washbasins that received 60 and 100 larvae were placed in each land cover type. Each washbasin was covered with a screen $($ mesh size $=$ $1 \mathrm{~mm}$ ) to prevent wild mosquitoes from ovipositing in the washbasin. We counted the number of larvae surviving in each washbasin daily. Once larvae started pupating, the washbasin was examined for emerged adults twice a day, at 9:0012:00 AM and 3:00-7:00 PM. Water temperature in each washbasin was monitored hourly with a Stowaway Tidbit data logger (Onset Computer, Bourne, MA). The experiment was repeated four times in each of three periods, between April 18 and July 28, 2004, between August 9 and October 23, 2004, and between January 28 and April 1, 2005. In total, we repeated the experiments 12 times.

Adult stage longevity and fecundity. Newly emerged adult mosquitoes were obtained from the insectary and transferred to Marani. Females and males were kept in separate cages $(30 \times 30 \times 30 \mathrm{~cm})$ in a house for 4 days. Each cage was provided a cotton pad with $10 \%$ sucrose solution. On day 5 (June 25, 2004), we randomly selected 50 females and 50 males and placed them in one of eight cages (in total, we had 400 females and 400 males in eight cages). Then, we placed two cages with mosquitoes in each of four randomly selected houses. All cages were provided the sugar solution, but females in one of two cages in each house were also fed on rabbit blood every day. The cotton pad was changed daily to prevent sugar fermentation. A wet filter paper $(7 \mathrm{~cm}$ in diameter) in a Petri dish was also provided in each cage as an oviposition substrate. The filter paper was removed daily, and any eggs laid were counted. Dead mosquitoes were removed and counted daily. The cages were observed daily until all females died. Indoor and outdoor temperatures were recorded hourly during the experiment using a Hobo data logger (Onset Computer) at each house. We ran the same experiment in Kombewa for comparison starting on the same day. An identical experiment was repeated in both sites starting on August 18, 2004.

Statistical analysis. We used three-way analysis of variance (ANOVA) to examine whether total development time was associated with land cover type, initial larval density, and study site. Associations of survival rate with these three factors were also tested. Total development time was defined as the total time (in days) required for first-instar larvae to become adults, and survival rate was defined as the number of adults over the initial number of larvae. Similarly, we tested associations of these factors with age-specific development time and survival rate for each immature developmental stage. We also tested associations of land cover type and study site with daily mean, maximum, and minimum temperatures using two-way ANOVA.

For the analysis of adult stage longevity, we grouped mosquitoes into three categories based on food source and sex: 1) blood-fed females, 2) sugar-fed females, and 3) sugar-fed males. The Cox-Mantel test was used to examine differences in survival time among the mosquito groups and between the study sites. For fecundity, we only considered blood-fed females, because sugar-fed females did not produce eggs. A $t$ test was used to test the difference in fecundity between the study sites.

We used immature stage survival rate, development time, and fecundity to estimate the potential number of adult mosquitoes that are produced annually by a single female mosquito.

Adult number $=$

$$
\frac{\text { fecundity } \times \text { immature stage survival rate } \times 365}{\text { immature stage development time }}
$$

Adult numbers were compared between the study sites and between the land cover types using two-way ANOVA. This analysis should be viewed in a relative sense, because it did not account for egg mortality or mortality by predation.

Because immature stage development times and adult stage longevities of several individuals extended over more than one season, we excluded the seasonal factor from all analyses. Tukey multiple comparison tests were used for post hoc analyses. The level of significance was set at 0.05 for all tests.

\section{RESULTS}

Temperature. Daily mean, minimum, and maximum water temperatures were significantly associated with land cover type (Table 1). Daily mean and maximum water temperatures were also significantly associated with study site, but minimum water temperature was not significantly associated with study site. The habitat $\times$ site interaction was not significant for mean water temperature, but it was significant for maximum and minimum water temperatures. The mean and maximum water temperatures in Marani were significantly lower than those in Kombewa (Table 2). All water temperature profiles were significantly higher in cultivated areas than in wetlands. Daily mean, minimum, and maximum air temperatures were significantly lower in Marani than in Kombewa, and temperatures were lower indoors than outdoors.

Immature stage development and survival. Female and male immature stage development times ranged from 10 to 45 days and from 9 to 32 days in Marani, respectively, and from 
TABLE 1

Results of two-way ANOVA to examine the relationships of land cover types and study site with water and air temperatures

\begin{tabular}{lcrrr}
\hline & df & Land cover* & Study site & Interaction \\
\hline $\begin{array}{l}\text { Mean water } \\
\text { temperature }\end{array}$ & 3,766 & $1242.14 \dagger$ & $62.93 \dagger$ & 0.23 \\
$\begin{array}{l}\text { Maximum water } \\
\text { temperature }\end{array}$ & 3,766 & $936.16 \dagger$ & $92.90 \dagger$ & $3.83 \dagger$ \\
$\begin{array}{l}\text { Minimum water } \\
\quad \text { temperature }\end{array}$ & 3,766 & $87.60 \dagger$ & 0.04 & $7.93 \dagger$ \\
$\begin{array}{l}\text { Mean air } \\
\text { temperature }\end{array}$ & 3,1991 & $457.10 \dagger$ & $1,481.08 \dagger$ & $158.52 \dagger$ \\
$\begin{array}{l}\text { Maximum air } \\
\text { temperature }\end{array}$ & 3,1991 & $813.47 \dagger$ & $391.36 \dagger$ & $5.09 \dagger$ \\
$\begin{array}{l}\text { Minimum air } \\
\text { temperature }\end{array}$ & 3,1991 & $2,065.73 \dagger$ & $692.13 \dagger$ & $130.24 \dagger$ \\
$\begin{array}{l}* \text { Water temperature was recorded in cultivated areas and wetlands, whereas air tempera- } \\
\text { ture was recorded indoor and outdoor. } \\
\quad P P<0.05 .\end{array}$ & & &
\end{tabular}

8 to 27 days and from 8 to 24 days in Kombewa, respectively. Three-way ANOVA revealed that female and male immature stage development times differed significantly among land cover type (female: $F_{1,167}=181.7, P<0.001$; male: $F_{1,161}=$ 144.7, $P<0.001$ ), initial larval density (female: $F_{2,167}=13.8$, $P<0.001$; male: $\left.F_{2,161}=6.6, P=0.002\right)$, and study site (female: $F_{1,167}=81.2, P<0.001$; male: $F_{1,161}=79.0, P<$ $0.001)$. Female and male mean development times were significantly shorter in Kombewa than in Marani and in cultivated areas than in wetlands (Table 3 ). Immature stage survival rate was significantly associated with land cover type $\left(F_{1,204}=228.3, P<0.001\right)$ and initial density $\left(F_{2,204}=41.4\right.$, $P<0.001)$, but its association was not significant with study site $\left(F_{1,204}=2.3, P=0.127\right)$. Immature stage survival rate was significantly higher in cultivated areas than in wetlands. Development times tended to be greater with a higher larval density, and immature stage survival rate tended to be lower (Table 3).

Age-specific development time was significantly greater in Marani than in Kombewa at all stages except the pupal stage, and it was significantly greater in natural swamps than in cultivated swamps except for first instars (Figure 1). Agespecific development time tended to be shorter with a lower density, but the differences among the densities were insignificant for first instars, pupae, and adult males. Age-specific

TABLE 2

Average (SE) daily mean, minimum, and maximum water temperatures $\left({ }^{\circ} \mathrm{C}\right)$ in aquatic habitats in cultivated areas and wetlands, and mean, minimum, and maximum air temperatures of indoor and outdoor in Marani and Kombewa

\begin{tabular}{lccc}
\hline \multicolumn{1}{c}{ Study site } & Mean & Minimum & Maximum \\
\hline Marani & & & \\
$\quad$ Cultivated area & $23.9(0.3)$ & $17.9(0.2)$ & $34.4(0.7)$ \\
$\quad$ Wetland & $19.2(0.1)$ & $16.8(0.2)$ & $22.2(0.2)$ \\
$\quad$ Indoor & $21.5(0.1)$ & $19.2(0.1)$ & $24.7(0.1)$ \\
Outdoor & $19.5(0.1)$ & $14.4(0.1)$ & $27.4(0.1)$ \\
Kombewa & & & \\
$\quad$ Cultivated area & $25.0(0.1)$ & $18.4(0.2)$ & $37.3(0.4)$ \\
$\quad$ Wetland & $20.2(0.1)$ & $16.8(0.2)$ & $26.6(0.5)$ \\
$\quad$ Indoor & $23.1(0.1)$ & $20.1(0.1)$ & $26.5(0.1)$ \\
Outdoor & $22.5(0.1)$ & $17.6(0.1)$ & $29.7(0.1)$ \\
\hline
\end{tabular}

TABLE 3

Means (SE) of immature stage survival rates and development times (day) with three different larval densities in two different land cover types in Marani and Kombewa

\begin{tabular}{lrccc}
\hline & & & \multicolumn{2}{c}{ Development time } \\
\cline { 4 - 5 } Study site and habitat & Density & Survival rate & Female & Male \\
\hline Marani & & & & \\
$\quad$ Cultivated area & 20 & $0.59(0.05)$ & $14.2(0.8)$ & $13.4(0.6)$ \\
& 60 & $0.39(0.04)$ & $16.7(1.1)$ & $16.1(1.0)$ \\
Wetland & 100 & $0.35(0.02)$ & $16.9(0.5)$ & $16.8(0.5)$ \\
& 20 & $0.27(0.03)$ & $22.2(0.9)$ & $23.0(1.4)$ \\
& 60 & $0.05(0.01)$ & $27.1(1.8)$ & $25.8(1.7)$ \\
Kombewa & 100 & $0.01(0.00)$ & $30.0(2.0)$ & $27.5(2.3)$ \\
Cultivated area & & & & \\
& 20 & $0.53(0.05)$ & $12.1(0.5)$ & $11.6(0.5)$ \\
Wetland & 60 & $0.36(0.04)$ & $13.7(0.8)$ & $13.4(0.8)$ \\
& 100 & $0.29(0.05)$ & $15.0(0.5)$ & $14.9(0.6)$ \\
& 20 & $0.18(0.04)$ & $17.9(0.9)$ & $18.2(1.2)$ \\
& 60 & $0.05(0.02)$ & $19.1(1.1)$ & $16.4(1.2)$ \\
& 100 & $0.07(0.02)$ & $18.5(1.0)$ & $17.1(0.9)$ \\
\hline
\end{tabular}

survival rate of first instars was significantly higher in Kombewa, but that of second instars was significantly lower in Kombewa (Figure 2). The differences in age specific survival rate between the sites were insignificant for the other stages.

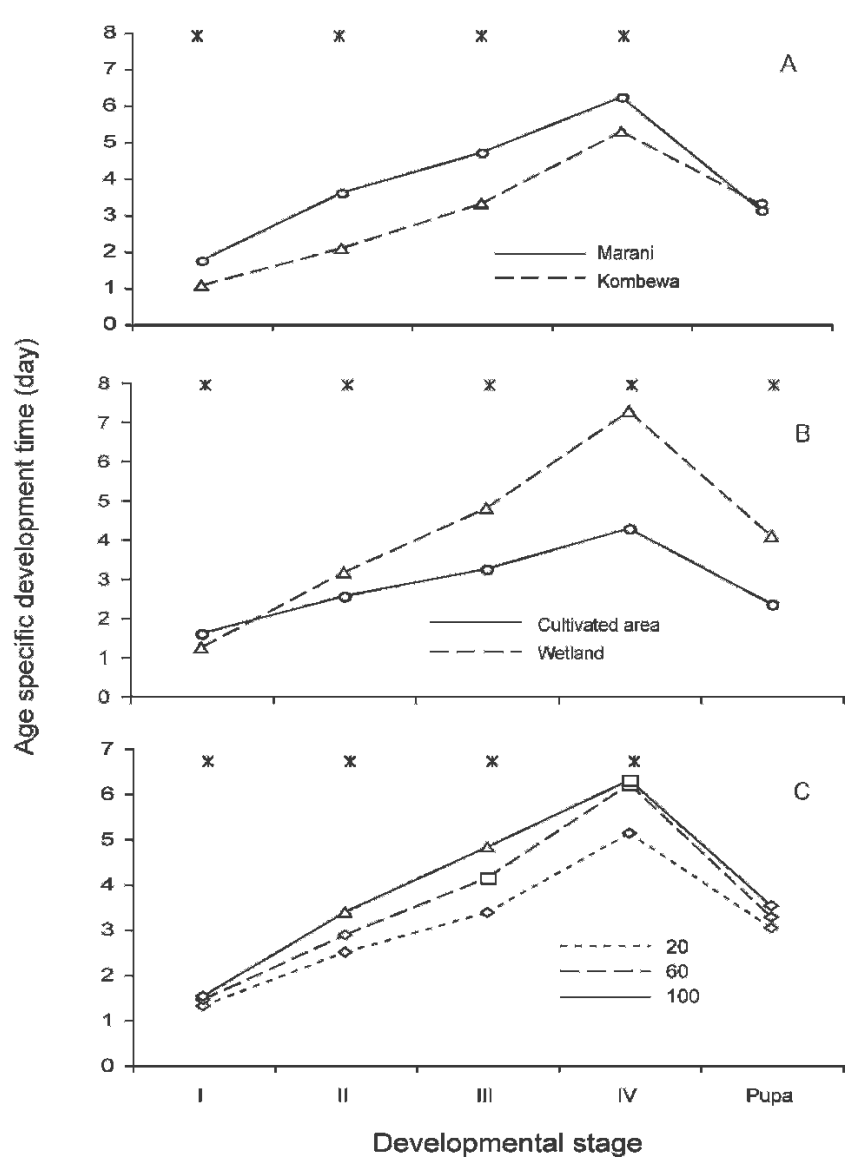

Figure 1. Comparisons of age-specific development times between (A) the study sites (Marani and Kombewa), (B) land cover types (cultivated area and wetland), and (C) initial larval densities $(20,60,100)$ at each developmental stage. ${ }^{*}$ Difference is significant at $P=0.05$. When points have the same symbol, the difference between values is not statistically significant. 


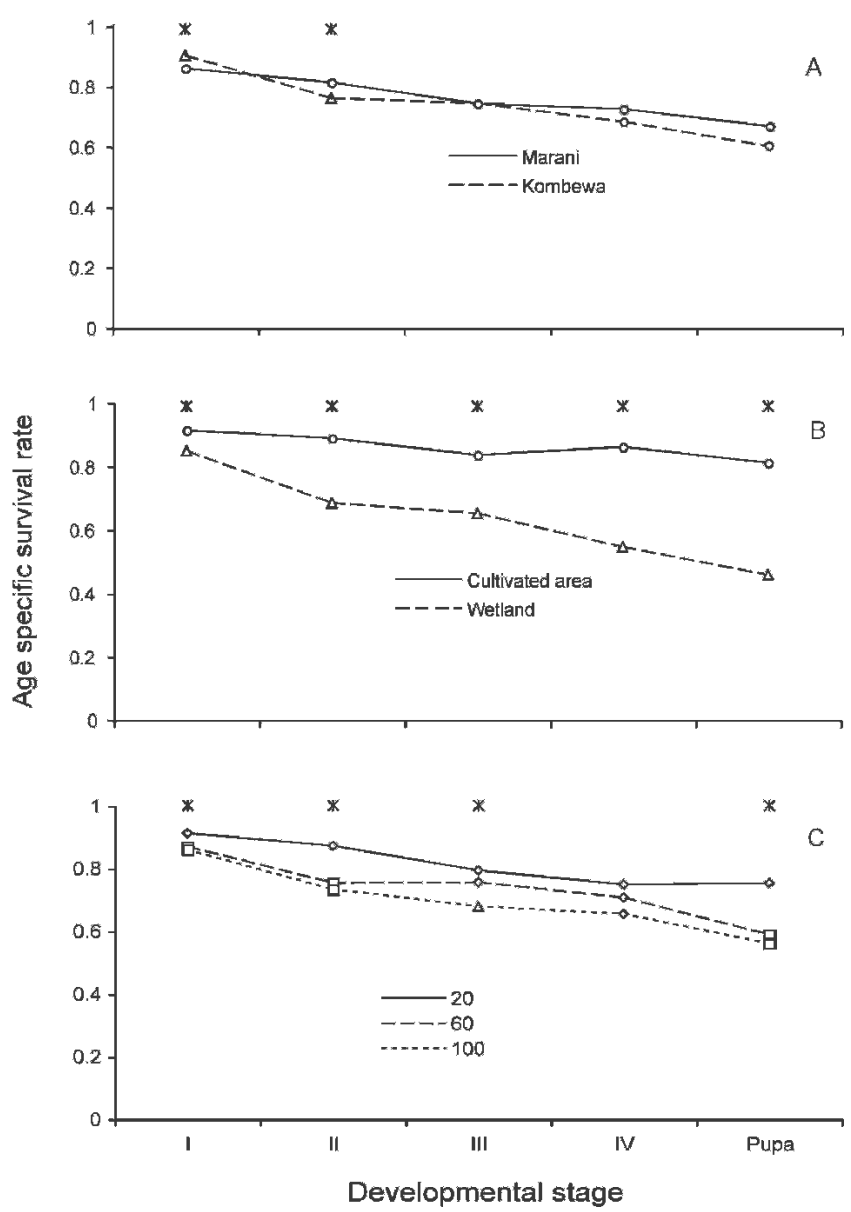

FIGURE 2. Comparisons of age-specific survival rates between (A) the study sites (Marani and Kombewa), (B) land cover types (cultivated area and wetland), and (C) initial larval densities (20, 60, $100)$ at each developmental stage. $*$ Difference is significant at $P=$ 0.05 . When points have the same symbol, the difference between values is not statistically significant.

Age-specific survival rate was significantly higher in cultivated areas than in wetlands at all stages. Among the densities, age-specific survival rate tended to be higher with a lower density at all stages except fourth instars.

Adult stage longevity and productivity. Adult stage longevity of blood fed females ranged from 5 to 89 days in Marani and 8 to 87 days in Kombewa. Sugar-fed female and male longevity ranged from 5 to 64 days and 1 to 57 days in Kombewa, respectively. Both sugar-fed female and male longevity raged from 1 to 51days in Marani. The Cox-Mantel test revealed that the difference in female longevity was significant between the food sources (sugar-fed female: mean $=28.2$ days, $\mathrm{SE}=2.0$; blood-fed female: mean $=38.6$ days, $\mathrm{SE}=$ $1.7 ; \mathrm{Z}=10.05, P<0.05$ ) and between the sites (Marani: mean $=31.0$ days, $\mathrm{SE}=2.1$; Kombewa: mean $=35.6$ days, $\mathrm{SE}=2.3 ; \mathrm{Z}=5.85, P<0.05)$. The difference in sugar-fed mosquito longevity was significant between the sexes (male: mean $=22.8$ days, $\mathrm{SE}=1.5$; female: mean $=28.2$ days, $\mathrm{SE}=2.0 ; \mathrm{Z}=4.80, P<0.05)$ and between the sites (Marani: mean $=22.6$ days, $\mathrm{SE}=1.5$; Kombewa: mean $=$ 28.3 days, $\mathrm{SE}=1.8 ; \mathrm{Z}=5.95, P<0.05)$.

Total number of eggs laid by 50 blood-fed mosquitoes was significantly greater in Kombewa than in Marani (Kombewa: mean $=11,219.0, \mathrm{SE}=1,111.4 ;$ Marani: mean $=7,219.2$, $\mathrm{SE}=1,541.6 ; t$ test: $t=2.41, \mathrm{df}=13, P=0.031)$. The potential number of adult mosquitoes produced by one female was significantly greater in cultivated areas than in wetlands (cultivated areas: mean $=526.0, \mathrm{SE}=39.0$; wetlands: mean $\left.=83.8, \mathrm{SE}=11.4 ; F_{1,212}=131.04, P<0.001\right)$, and greater in Kombewa than in Marani (Kombewa: mean = 385.3, $\mathrm{SE}=42.9$; Marani: mean $=223.0, \mathrm{SE}=24.6 ; F_{1,212}=$ $18.89, P<0.001)$. The habitat $\times$ site interaction was significant $\left(F_{1,212}=9.96, P=0.002\right)$.

\section{DISCUSSION}

This study showed that productivity of the malaria vector A. gambiae was lower in Marani than Kombewa because immature stage development was slower and fecundity was lower in the highland site. Accordingly, the potential number of adult mosquitoes produced by one female was less at the highland site than at the lowland site. These results explain past observations of low vector density in the East African highlands. ${ }^{5,6,8,18}$ Low vector abundance is likely one of the major factors contributing to low malaria transmission in the highland, whereas the Lake Victoria Basin remains a malaria holoendemic area with high vector densities. The shorter longevity in the highland may also reduce the chance a single female mosquito may transmit malaria during its lifespan.

The findings from this study and past studies are sufficient to conclude that low ambient temperature is primarily responsible for the low abundance of malaria vectors in the East African highlands. ${ }^{6,8}$ Bayoh and Lindsay ${ }^{22}$ found that, under laboratory conditions, the development rate of $A$. gambiae from one immature stage to the next increases at higher constant temperatures to a peak around $28^{\circ} \mathrm{C}$. Their study also showed that adult emergence rate was greatest between $28^{\circ} \mathrm{C}$ and $32^{\circ} \mathrm{C}$. Although results from laboratory experiments using constant temperatures may not fully apply to our study, the findings by Bayoh and Lindsay ${ }^{22}$ support the idea that higher water temperatures in Kombewa were more suitable for immature stage development than the lower water temperatures in Marani. The results from our study also suggest that low air temperature in the highland may shorten adult stage longevity of $A$. gambiae, which consequently reduces the total number of eggs laid by a female.

It has been suggested that global warming has caused the recent re-emergence of malaria in the East African highlands. ${ }^{26,27}$ Although recent studies found no significant association between global warming and malaria epidemics in the highlands, ${ }^{1,21,28}$ our results suggest that a small temperature increase in the highlands may lead to a rapid population increase of malaria vectors and consequently lead to a malaria epidemic. The differences in water temperature between $\mathrm{Ma}$ rani and Kombewa ranged from $0.5^{\circ} \mathrm{C}$ for minimum temperature to $2.9^{\circ} \mathrm{C}$ for maximum temperature in cultivated areas where mosquito productivity was high. In houses, where $A$. gambiae mostly rests, ${ }^{29}$ the temperature differences between Marani and Kombewa ranged from $0.9^{\circ} \mathrm{C}$ for minimum temperature to $1.8^{\circ} \mathrm{C}$ for maximum temperature. An increase of $0.5-2.9^{\circ} \mathrm{C}$ in each temperature profile is quite possible at the microhabitat level that mosquitoes inhabit.

Increased human activity, such as deforestation and wetland reclamation, has altered microclimates in the East Afri- 
can highlands. Recent studies found that larvae of $A$. gambiae s.l. occur more frequently in temporary pools in cultivated areas than in those of wetlands and forests in the highlands of western Kenya. ${ }^{18,19}$ Because cultivated areas without tall vegetation receive more sunlight than wetlands and forests, water temperature of aquatic habitats in cultivated areas becomes warmer. As our study showed, immature stage development and survival rate are enhanced in cultivated swamps where water temperature is higher. Moreover, Lindblade and oth$\mathrm{ers}^{5}$ found that maximum and minimum air temperatures were significantly higher in communities bordering cultivated swamps in a Ugandan highland, and they found more malaria vectors in houses near cultivated swamps. Thus, such environmental changes may increase vector abundance by enhancing breeding habitats and also by enhancing adult stage longevity and fecundity of $A$. gambiae in houses near cultivated areas.

Temperature varies seasonally. In general, temperature in the highlands of western Kenya is highest in the dry season (December to February). During the 1997-1998 malaria outbreaks in the Kenyan highland, rain continued into the dry season (warm season) from the short rainy season (October and November). This created numerous mosquito breeding sites. Because of the negative correlation between temperature and larval development, the increased number of breeding sites in the warm season may have led to a rapid population increase of malaria vectors, which consequently led to the malaria epidemics in the highlands. Based on findings from a study in the Usambara Mountains, Bodker and others ${ }^{8}$ also suggested that unexpected rains at the beginning of the warm season (the dry season in a normal year) is an important generator of highland malaria epidemics.

Because indoor vector density is generally low in the highland areas, larval density should also be low in habitats newly created by unexpected rain in the warm season and by land modifications. In particular, larval density should be low at the beginning of the warm season or at the beginning of the rainy period. The results indicate that immature stage survival rate and development were enhanced with low larval densities. Gimnig and others ${ }^{30}$ also reported that high densities extended larval development time in the Lake Victoria Basin. These results suggest that low larval densities in the highland area may further accelerate development of a vector population at the beginning of the season. Understanding the mechanisms of highland malaria depends on a better understanding of the interactions between the highland environment and transmission. Although models of malaria transmission in highlands have considered the relationships between temperature and parasite development, they have not incorporated vector abundance in relation to environmental parameters. ${ }^{15,31}$ Because vector abundance is a primary driver of malaria transmission, ${ }^{32}$ it has been strongly suggested that models need to incorporate estimates of vector densities. ${ }^{8}$ Our study provides important information for understanding highland malaria by revealing the relationships between vector productivity and the highland environment.

Received August 22, 2005. Accepted for publication March 19, 2006.

Acknowledgments: This paper is published with permission of the Director, Kenya Medical Research Institute. We thank Ben Omboko, Paul Ochiele, Bernard Ouma, Amos Ouko, Gilbert Marita, Abireo Festus, Ateko Ken, and Justus Wafula for technical assistance.
Financial support: This work was supported by NIH Grants R01 A150243 and D43 TW01505.

Authors' addresses: Noboru Minakawa, Institute of Tropical Medicine, Nagasaki University, 1-12-4 Sakamoto, Nagasaki 852-8523, Japan. Elizabeth Omukunda and Andrew Githeko, Climate and $\mathrm{Hu}-$ man Health Research Unit, Center for Vector Biology and Control Research, Kenya Medical Research Institute, PO Box 1578-40100, Kisumu, Kenya. Guofa Zhou and Guiyun Yan, Department of Biological Sciences, State University of New York, Buffalo, NY 14260.

\section{REFERENCES}

1. Malakooti MA, Biomndo K, Shanks GD, 1998. Reemergence of epidemic malaria in the highlands of western Kenya. Emerg Infect Dis 4: 671-676.

2. Shanks GD, Biomndo K, Hay SI, Snow RW, 2000. Changing patterns of clinical malaria since 1965 among a tea estate population located in the Kenyan highlands. Trans $R$ Soc Trop Med Hyg 94: 253-255.

3. Garnham PCC, 1928. The incidence of malaria at high altitudes. J Natl Malaria Soc 7: 275-284.

4. Roberts JM, 1964. The control of epidemic malaria in the highlands of western Kenya. III. After the campaign. J Trop Med Hyg 67: 230-237.

5. Lindblade KA, Walker ED, Onapa AW, Katungu J, Wilson ML, 2000. Land use change alters malaria transmission parameters by modifying temperature in a highland area of Uganda. Trop Med Int Health 5: 263-274.

6. Minakawa N, Sonye G, Mogi M, Githeko A, Yan G, 2002. The effects of climatic factors on the distribution and abundance of malaria vectors in Kenya. J Med Entomol 39: 833-841.

7. Lindblade KA, Walker ED, Wilson ML, 2000. Early warning of malaria epidemics in African highlands using Anopheles (Diptera: Culicidae) indoor resting density. J Med Entomol 37: 664-674.

8. Bodker R, Akida J, Shayo D, Kisinza W, Msangeni HA, Pedersen EM, Lindsay SW, 2003. Relationship between altitude and intensity of malaria transmission in the Usambara Mountains, Tanzania. J Med Entomol 40: 706-717.

9. Beier JC, Perkins PV, Onyango FK, Gargan TP, Oster CN, Whitmire RE, Koech DK, Roberts CR, 1990. Characterization of malaria transmission by Anopheles (Diptera: Culicidae) in western Kenya in preparation for malaria vaccine trials. J Med Entomol 27: 570-577.

10. Githeko AK, Service MW, Mbogo CM, Atieli FK, Juma FO, 1993. Plasmodium falciparum sporozoite and entomological inoculation rates at the Ahero rice irrigation scheme and the Miwani sugar-belt in western Kenya. Ann Trop Med Parasitol 87: 379-391.

11. John CC, Ouma JH, Sumba PO, Hollingdale MR, Kazura JW, King CL, 2002. Lymphocyte proliferation and antibody responses to Plasmodium falciparum liver-stage antigen-1 in a highland area of Kenya with seasonal variation in malaria transmission. Am J Trop Med Hyg 66: 372-378.

12. John CC, Koech DK, Sumba PO, Ouma JH, 2004. Risk of Plasmodium falciparum infection during a malaria epidemic in highland Kenya, 1997. Acta Trop 92: 55-61.

13. Smith T, Charlwood JD, Kihonda J, Mwankusye S, Billingsley P, Meuwissen J, Lyimo E, Takken W, Teuscher T, Tanner M, 1993. Absence of seasonal variation in malaria parasitaemia in an area of intense seasonal transmission. Acta Trop 54: 55-72.

14. Mouchet J, Carnevale P, 1997. Impact of changes in the environment on vector-transmitted diseases. Sante 7: 263-269.

15. Lindsay SW, Martens WJ, 1998. Malaria in the African highlands: Past, present and future. Bull World Health Organ 76: 33-45.

16. Mouchet J, Manguin S, Sircoulon J, Laventure S, Faye O, Onapa AW, Carnevale P, Julvez J, Fontenille D, 1998. Evolution of malaria in Africa for the past 40 years: Impact of climatic and human factors. J Am Mosq Control Assoc 14: 121-130.

17. Patz JA, Graczyk TK, Geller N, Vittor AY, 2000. Effects of environmental change on emerging parasitic diseases. Int $J$ Parasitol 30: 1395-1405.

18. Minakawa N, Sonye G, Mogi M, Yan G, 2004. Habitat charac- 
teristics of Anopheles gambiae s.s. larvae in a Kenyan highland. Med Vet Entomol 18: 301-305.

19. Minakawa N, Munga S, Atieli F, Mushinzimana E, Zhou G, Githeko A, Yan G, 2005. Spatial distribution of anopheline larval habitats in western Kenyan highlands: Effects of land cover types and topography. Am J Trop Med Hyg 73: 157-165.

20. Abeku TA, van Oortmarssen GJ, Borsboom G, de Vlas SJ, Habbema JD, 2003. Spatial and temporal variations of malaria epidemic risk in Ethiopia: Factors involved and implications. Acta Trop 87: 331-340.

21. Zhou G, Minakawa N, Githeko AK, Yan G, 2004. Association between climate variability and malaria epidemics in the East African highlands. Proc Natl Acad Sci USA 101: 2375-2380.

22. Bayoh MN, Lindsay SW, 2003. Effect of temperature on the development of the aquatic stages of Anopheles gambiae sensu stricto (Diptera: Culicidae). Bull Entomol Res 93: 375-381.

23. Bayoh MN, Lindsay SW, 2004. Temperature-related duration of aquatic stages of the Afrotropical malaria vector mosquito Anopheles gambiae in the laboratory. Med Vet Entomol 18: 174-179.

24. Trape JF, Pison G, Spiegel A, Enel C, Rogier C, 2002. Combating malaria in Africa. Trends Parasitol 18: 224-230.

25. Killeen GF, Seyoum A, Knols BG, 2004. Rationalizing historical successes of malaria control in Africa in terms of mosquito resource availability management. Am J Trop Med Hyg 71: 87-93.

26. Loevinsohn ME, 1994. Climatic warming and increased malaria incidence in Rwanda. Lancet 343: 714-718.

27. Lindsay SW, Birley MH, 1996. Climate change and malaria transmission. Ann Trop Med Parasitol 90: 573-588.

28. Hay SI, Cox J, Rogers DJ, Randolph SE, Stern DI, Shanks GD, Myers MF, Snow RW, 2002. Climate change and the resurgence of malaria in the East African highlands. Nature 415: 905-909.

29. Githeko AK, Service MW, Mbogo CM, Atieli FK, Juma FO, 1994. Origin of blood meals in indoor and outdoor resting malaria vectors in western Kenya. Acta Trop 58: 307-316.

30. Gimnig JE, Ombok M, Otieno S, Kaufman MG, Vulule JM, Walker ED, 2002. Density-dependent development of Anopheles gambiae (Diptera: Culicidae) larvae in artificial habitats. J Med Entomol 39: 162-172.

31. Rogers DJ, Randolph SE, 2000. The global spread of malaria in a future, warmer world. Science 289: 1763-1766.

32. Garrett-Jones C, 1964. Prognosis for interruption of malaria transmission through assessment of the mosquito's vectorial capacity. Nature 204: 1173-1175. 